\title{
Effects of Internal Bleaching on the Adhesion of Glass-Fiber Posts
}

\author{
Paulo E. de Oliveira Moreira ${ }^{1}$, Lucianne S. Pamplona ${ }^{1}$, Gláucia C. R. Nascimento ${ }^{1}$, \\ Renata A. Esteves ${ }^{2}$, Oscar F. Pessoa ${ }^{3}$ and Cecy M. Silva, ${ }^{1, *}$ \\ ${ }^{I}$ Department of Dentistry, School of Dentistry of Federal University of Pará, Belém, Pará, Brazil \\ ${ }^{2}$ Department of Prosthodontics, School of Dentistry of Federal University of Pará, Belém, Pará, Brazil \\ ${ }^{3}$ Department of Endodontics, School of Dentistry of Federal University of Pará, Belém, Pará, Brazil
}

\begin{abstract}
Objective: We evaluated the effects of internal bleaching on the adhesion of glass-fiber posts (GFPs) luted with different resin cements. Methods: Forty extracted human single-root teeth were endodontically treated and divided into four groups ( $\mathrm{n}=10)$ : G1- conventional resin cement (CRC); G2- self-adhesive resin cement (SARC); G3- bleaching + CRC; and G4- bleaching + SARC. Specimens were sectioned transversally into three slices to perform the push-out test at the coronal, middle and apical regions of the root canals. Data were analyzed using analysis of variance and Tukey's test $(p<0.05)$. Results: The push-out bond strength of GFPs luted with SARC after bleaching (G4) was significantly lower than that of the other groups $(p<0.001)$. We found no statistically significant differences in push-out bond strength among the other groups. Significance: Internal bleaching reduced the adhesion of GFPs luted with SARC. The adhesion of GFPs luted with $\mathrm{CRC}$ was not decreased after bleaching.
\end{abstract}

Keywords: Dental bleaching, dental bonding, dentin-bonding agents, hydrogen peroxide, resin cements, tooth bleaching.

\section{INTRODUCTION}

Fiber posts are non-metallic alternatives that increase the optical effect of the restoration, providing better aesthetics $[1,2]$. As advantages have mechanical characteristics approaching to dentin, furthermore, the fiber posts have biocompatibility, mechanical strength and resistance to corrosion $[2,3]$. The use of this material reduces the probability of root fracture and reduces the time required to complete the restoration eliminating the laboratory procedures $[4,5]$. The retention of glass-fiber posts (GFPs) in the root canal depends on the quality of the hybrid layer [6].

Certain endodontically treated teeth might require internal bleaching before coronal reconstruction to obtain satisfactory aesthetic results. However, the application of hydrogen peroxide to tooth structures has been shown to decrease the microhardness [7], and modulus of elasticity [8], produce morphological alterations in the dental surface [9], affect the intertubular and peritubular dentin [10] and cause structural alterations to the hydroxyapatite due to ionic bonds that weaken its structure [11].

Several studies have investigated the relationship between the bonding effectiveness of GFPs and resin cement types [3, 12-15] and application modalities [1, 16-19]. However, to date, no information is available on the combined effects of bleaching agents on the adhesion of GFPs luted with resin cements.

*Address correspondence to this author at the School of Dentistry, Federal University of Para, Rua dos Mundurucus, 822 / 903, 66025-660, Jurunas, Belem, Pará, Brazil; Tel: +55 9191144905;

E-mail: cecymsilva@gmail.com
The present study evaluated the influence of internal bleaching with $35 \%$ hydrogen peroxide on the adhesion of GFPs luted with two different resin cements (conventional versus self-adhesive). The null hypothesis was that $35 \%$ hydrogen peroxide would not affect the adhesion of GFPs cemented with the various luting agents.

\section{MATERIALS AND METHODS}

\section{Human Tooth Specimens}

Following approval of our investigation by the local ethics committee, informed consent was obtained from all of the subjects. Forty extracted single-rooted human teeth with intact crowns and similar root sizes and lengths were selected for this study. Radiographs were obtained to ensure the presence of straight single main root canals and completely formed apices in all of the teeth. After the teeth were cleaned of adhering tissue remnants from their surfaces, they were rinsed and stored in distilled water until use. The specimens were randomly assigned to one of the four groups $(n=10)$ characterized by resin cement (conventional or selfadhesive) and bleaching procedure (Table $\mathbf{1}$ ).

\section{Endodontic Treatment}

The coronal access opening was prepared using a diamond burr under high-speed water spray cooling. The working length of the tooth was established $1 \mathrm{~mm}$ from the root apex. All of the canals were instrumented by the step-back technique using K-files. All of the enlargement procedures were followed by irrigation with $2.5 \%$ sodium hypochlorite solution. The prepared root canals were filled with guttapercha cones (Kerr/Sybron, Corp, Romulus, MI, USA) using the lateral condensation technique and resin sealer 
Table 1. Distribution of the groups according to treatment received before bonding and luting agent tested.

\begin{tabular}{|c|c|c|c|c|}
\hline Type & Group & N & Luting Agent & Manufacturer \\
\hline \hline Control & G1 & 10 & RelyX ARC & $3 \mathrm{M}$, ESPE, St Paul, MN, USA \\
\hline (Unbleached teeth - immersed in distilled water) & G2 & 10 & RelyX Unicem & $3 \mathrm{M}$, ESPE, St Paul, MN, USA \\
\hline Experimental & G3 & 10 & RelyX ARC & $3 \mathrm{M}$, ESPE, St Paul, MN, USA \\
\hline $\begin{array}{c}\text { "Walking bleach" } \\
(35 \% \text { hydrogen peroxide })\end{array}$ & G4 & 10 & RelyX Unicem & $3 \mathrm{M}$, ESPE, St Paul, MN, USA \\
\hline
\end{tabular}

Table 2. Luting agents used and their application modes according to the manufacturer's instructions.

\begin{tabular}{|l|l|}
\hline Luting Agent & Application Mode \\
\hline \hline $\begin{array}{l}\text { Scotchbond Multipurpose }+ \\
\text { RelyX ARC } \\
\text { (Conventional resin cement) }\end{array}$ & $\begin{array}{l}\text { Apply } 35 \% \text { phosphoric acid for } 15 \mathrm{~s} \text {; rinse with water for } 15 \mathrm{~s} \text {, followed by air drying for } 2 \mathrm{~s} \text {; remove excess moisture } \\
\text { with paper points; apply activator of the adhesive system in the canal and then apply the primer; apply the catalyst; } \\
\text { mix the cement for } 10 \mathrm{~s} \text {; apply cement in and around the canal; place a thin layer of mixed cement on the post and seat } \\
\text { the post reme the excess while holding the post in place; light-polymerize for } 40 \mathrm{~s} \text { from the occlusal direction }\end{array}$ \\
\hline $\begin{array}{l}\text { RelyX Unicem } \\
\text { Self-adhesive resin cement) }\end{array}$ & $\begin{array}{l}\text { Irrigate the canals with distilled water; remove excess with paper points; mix the cement for } 20 \mathrm{~s} \text {; apply cement in and } \\
\text { around the canal; place a thin layer of mixed cement on the post and seat the post; remove the excess cement while }\end{array}$ \\
\hline
\end{tabular}

(Sealer-26, Dentsply Ind. Com. Ltda, Petrópolis, RJ, Brazil). Gutta-percha excess was removed $2 \mathrm{~mm}$ below the cementoenamel junction (CEJ) after obturation was completed.

\section{Bleaching Procedure}

The bleached teeth received 2-mm-thick cervical seals of glass ionomer cement (Vitro Fil, DFL, Rio de Janeiro, RJ, Brazil) at the CEJ. The teeth were stored at $37^{\circ} \mathrm{C}$ for $45 \mathrm{~m}$ to ensure the complete setting of the glass ionomer cement. The "walking bleach" technique was performed. A 35\% hydrogen peroxide gel (Whiteness HP, FGM, Joinville, SC, Brazil) was applied to the buccal surface and in the pulp chamber. A tiny cotton pellet was placed into the gel and the teeth were sealed with provisional restorations. This procedure was repeated three times with a five-day bleaching interval. Between sessions, the teeth were stored in $100 \%$ relative humidity at $37^{\circ} \mathrm{C}$. After the bleaching treatment, we applied a cotton pellet with a calcium hydroxide powder paste and distilled water into the pulp chamber; the pulp chamber was then temporarily sealed. The teeth were stored in distilled water at $37^{\circ} \mathrm{C}$ for $14 \mathrm{~d}[20,21]$.

The crowns were removed using a low-speed diamond disc under water cooling. Each root canal was enlarged with a low-speed drill provided by the manufacturer of the post system (White Post DC, size 2, FGM, Joinville, SC, Brazil). The post space preparation was 8-mm deep, leaving at least 4-mm of gutta-percha inside the canal to guarantee an apical seal. The posts were cleaned with $70 \%$ alcohol and received a layer of silane (3M ESPE); the excess silane was removed with compressed air applied for 5s. The GFPs were cemented according to the guidelines of the manufacturer of the resin cement (Table 2). After cementation, the roots were maintained in $100 \%$ relative humidity at $37^{\circ} \mathrm{C}$ for $24 \mathrm{~h}$ before testing.

\section{Push-out Bond Strength Test}

The post of each root containing the fiber post was sectioned transversally into three slices with a water-cooled lowspeed diamond saw (Micromet, Remet, Bologna, Italy); the first section was made 1-mm away from the CEJ. Each slice was approximately $2.5-\mathrm{mm}$ thick. The first slice represented the coronal region, the second slice the middle region and the third slice the apical region of the post space preparation.

Each post was carried with a cylindrical plunger (2-mm diameter) connected to a universal testing machine (DL 2000, Emic, São José dos Pinhais, São Paulo, Brazil). The plunger tip was sized and positioned such that it was in contact with only the fiber post. A load was applied on the apical aspect of the root slice in the apical-coronal direction. The load was applied at a speed of $0.5 \mathrm{~mm} / \mathrm{min}$ until failure, defined as the extrusion of the post segment from the root slice $[22,23]$.

The maximum failure load was recorded in newtons $(\mathrm{N})$ and converted into megapascals (MPa) by dividing the applied load by the bonded area (SL). The bonded area represents the lateral surface of a truncated cone and was therefore calculated with the following formula: $S L=\pi(R+r)$ $(\mathrm{h} 2+[\mathrm{R}-\mathrm{r}] 2) 0.5$, where $\pi=3.14, \mathrm{R}=$ coronal post radius, $\mathrm{r}$ $=$ apical post radius, and $\mathrm{h}=$ root slice thickness.

\section{Statistical Analysis}

Statistical analyses of the data were performed using a statistical software package (SPSS, version 16.0, SPSS Corp., Chicago, IL, USA). The Shapiro-Wilk and Levene tests were used to verify normality and homogeneity. Analysis of Variance (ANOVA) was used to analyze the data, followed by Tukey's multiple comparison test. For all analyses, the level of significance was $5 \%$. 
Table 3. Push-out bond strength in megapascals (MPa) (Mean, SD and CI 95\%) for the groups evaluated in different regions.

\begin{tabular}{|c|c|c|c|c|c|c|}
\hline \multirow{2}{*}{ Group } & \multicolumn{2}{|c|}{ Cervical } & \multicolumn{2}{c|}{ Middle } & \multicolumn{2}{c|}{ Apical } \\
\cline { 2 - 7 } & $\bar{\chi}( \pm$ SD) & CI 95\% & $\bar{\chi} \pm$ SD & CI 95\% & $\bar{\chi} \pm$ SD & CI 95\% \\
\hline \hline G1 & $17.33(5.31)^{\mathrm{A}, \mathrm{a}}$ & $6.71-27.95$ & $9.8(3.39)^{\mathrm{A}, \mathrm{b}}$ & $3.02-16.58$ & $5.47(4.07)^{\mathrm{A}, \mathrm{b}}$ & $-2.67-13.61$ \\
\hline G2 & $11.65(5.08)^{\mathrm{A}, \mathrm{a}}$ & $1.49-21.81$ & $8.97(3.25)^{\mathrm{A}, \mathrm{a}}$ & $2.47-15.47$ & $12.40(4.80)^{\mathrm{B}, \mathrm{a}}$ & $2.80-22.00$ \\
\hline G3 & $11.43(3.68)^{\mathrm{A}, \mathrm{a}}$ & $4.07-18.79$ & $8.69(2.73)^{\mathrm{A}, \mathrm{a}}$ & $3.23-14.15$ & $9.24(3.12)^{\mathrm{A}, \mathrm{B}, \mathrm{a}}$ & $3.00-15.48$ \\
\hline G4 & $5.43(1.80)^{\mathrm{B}, \mathrm{a}}$ & $1.83-9.03$ & $4.27(1.46)^{\mathrm{B}, \mathrm{a}}$ & $1.35-7.19$ & $5.33(2.24)^{\mathrm{A}, \mathrm{a}}$ & $0.85-9.81$ \\
\hline
\end{tabular}

Note: Different superscript case letters indicate statistically significant differences within columns, and different lower letters indicate significant differences within rows ( $\mathrm{p} \leq 0.05$ ) by Tukey test for multiple comparisons.

\section{RESULTS}

The descriptive statistics for the push-out bond strength and the results of Tukey test for multiple comparisons between groups are presented in Table 3. The push-out bond strength of GFPs luted with self-adhesive cement after bleaching (G4) was significantly lower than that of the other groups in the cervical and middle slices $(p<0.001)$. The location within the root region appeared to influence bond strength, as significant differences were observed in the conventional cement group (G1) between the cervical and middle slices $(p<0.001)$ and between the cervical and apical slices $(p<0.001)$. In this group, the cervical slices had greater push-out bond strength. We found no statistically significant differences in bond strength between the root regions of the other groups $(p>0.05)$.

\section{DISCUSSION}

To our knowledge, this was the first study to assess the impact of internal bleaching on the push-out bond strength of GFPs luted with two types of resin luting agent. The null hypothesis was partially rejected because GFPs luted with self-adhesive resin cement had the lowest push-out bond strength values.

This result could be due to alterations in the organic substance of dentin after bleaching. The residual oxygen from the bleaching agent might interfere with resin attachment and inhibit resin polymerization, thus increasing the porosity of the resin material and producing poorly formed and undefined interfaces [24]. Hydrogen peroxide was also shown to oxidize organic dentin compounds and modify their mineral components [25]. Hydrogen peroxide generates free radicals that combine with hydroxyapatite and produce a structure known as apatite peroxide that degrades calcium and phosphate, the two primary mineral components of dental hydroxyapatite [26].

Some studies have reported that bleaching results in the removal of calcium, phosphate and other ions from dental structures [27-30]. During the bonding process of selfadhesive resin cement, the calcium present in the dentin hydroxyapatite acts as an electron acceptor, promoting chemical union between the acidic resin monomers and the hard dental tissues [31]. The calcium ions are responsible for the neutralization of the phosphoric acidic components. There- fore, greater losses of calcium ions probably result in greater amounts of unreacted monomers and therefore in the higher sorption and greater solubility of the self-adhesive resin cement. Sorption and solubility can influence the strength of the resin cement [32]. Moreover, the self-adhesive cement had higher hydrophilicity than more hydrophobic conventional composite cements [33].

Bleaching procedures have been shown to increase metalloproteinase-mediated collagen degradation in dentin [34]. Metalloproteinases (MMPs) produce collagen degradation at the dentin-resin bonded interfaces, jeopardizing the efficacy of bonded restorations [34]. In addition, dentin demineralization by acidic monomers could release sequestered growth factors that could then diffuse through the dentinal tubules along with unpolymerized acidic monomers, stimulating the expression of MMP by odontoblasts [35] and possibly contributing to bond degradation [31]. These related adverse effects, the relatively high viscosity of self-adhesive resin cement and the low demineralizing capacity of the cement contribute to low monomer infiltration into dentin, thus reducing micromechanical retention [36]

In contrast, we found no significant decrease in the pushout bond strength of GFPs luted with conventional resin cement after bleaching [37, 38]. These results could be explained by differences in the compositions of the luting agents. These luting agents had distinct viscosities and different bonding mechanisms [39]. For example, the Scotchbond Multipurpose is an alcohol-based adhesive, and studies have concluded that alcohol-based adhesives could increase the bond strength for bleached teeth [38, 39]. Alcohol-based dental bonding agents can also reduce or eliminate the detrimental effects of residual oxygen on the bonding process. The high volatility, the solvent and hydrophobic nature of these bonding agents and the rapid evaporation of the agents into the environment facilitates the removal of residual oxygen from the tubules, thus contributing to increased bond strength between the adhesive composite and the teeth [37].

Despite the fact that the teeth were unbleached, our results are in agreement with those of previous studies that reported that self-adhesive cement and conventional resin cement had similar push-out bond strengths $[12,14,16]$. However, the push-out bond strength values obtained for resin cements in the literature have been quite controversial. Some studies have found that self-adhesive resin cement has 
greater push-out bond strengths than other types of resin cements $[15,19,13]$. Other investigations have reported greater bond strength for conventional resin cements $[17,18$, 30]. One possible explanation for these results is the different protocols and variables adopted in other investigations. In addition, the size and shape of the root canals and the texture and properties of the inner surfaces of the root canals may have differed among the teeth used [38]. This variability, however, also occurs in clinical situations [38].

Significant differences in push-out bond strength were observed between the root sections only for GFPs cemented with conventional cement in unbleached teeth; coronal sections, in particular, demonstrated greater bond strength. This observation might be due to the fact that this adhesive requires more complex procedures, resulting in compromised moisture control in the apical third [4]. Some studies have demonstrated that the bond strengths of conventional resin cements in root canals are greater in cervical areas and lower toward the apical third $[1,4,13,29$,]. However, no differences were found between the slices in the other groups.

The preliminary findings of this in vitro report could be confirmed with in situ evaluations.

\section{CONCLUSION}

Internal bleaching with $35 \%$ hydrogen peroxide reduced the adhesion of GFPs luted with self-adhering resin cement. The adhesion of GFPs luted with conventional resin cement was not decreased after bleaching.

\section{CONFLICT OF INTEREST}

The authors confirm that this article content has no conflict of interest.

\section{ACKNOWLEDGEMENTS}

Declared none.

\section{REFERENCES}

[1] Beriat NC, Ertan AA, Yilmaz Z, Gulay G, Sahin C. Effects of different luting cements and light curing units on the sealing ability and bond strength of fiber posts. Dent Mater J 2012; 31: 575-82.

[2] Demiryurek EO, Kulunk S, Sarac D, Yuksel G, Bulucu B. Effect of different surface treatments on the push-out bond strength of fiber post to root canal dentin. Oral Surg Oral Med Oral Pathol Oral Radiol Endodontol 2009; 108: 74-80.

[3] Perdigão J, Geraldeli S, Lee IK. Push-out bond strengths of toothcolored posts bonded with different adhesive systems. Am J Dent 2004; 17: 422-6.

[4] Calixto LR, Bandéca MC, Clavijo V, Andrade MF, Vaz LG, Campos EA. Effect of resin cement system and root region on the pushout bond strength of a translucent fiber post. Oper Dent 2012; 37: 80-6.

[5] Borges MG, Faria-e-Silva AL, Santos-Filho PCF, Silva FP, Martins LRM, Menezes MS. Does the moment of fiber post cutting influence on the retention to root dentin? Braz Dent J 2015; 26 [Epub ahead of print]

[6] Faria-e-Silva Al, Mendonça AA, Garcez RM, Oliveira AS, Moreira AG, Moraes RR. Adhesion strategy and early bond strengths of glass-fiber post luted into root canals. Braz Oral Res 2012; 26: 4857.

[7] Oliveira DP, Teixeira ECN, Ferraz CCR, Teixeira FB. Effect of intracoronal bleaching agents on dentin microhardness. J Endod 2007; 33: 460-2.
[8] Chng HK, Yap AUJ, Wattanapayungkul P, Sim CPC. Effect of traditional and alternative intracoronal bleaching agents on microhardness of human dentine. J Oral Rehab 2004; 31: 811-6.

[9] Sulieman M, Mcdonald E, Rees JS. A safety study in vitro for the effects of an in-office bleaching system on the integrity of enamel and dentine. J Dent 2004; 32: 581-90.

[10] Kawamoto K, Tsujimoto Y. Effects of the hydroxyl radical and hydrogen peroxide on tooth bleaching. J Endod 2004; 30: 45-50.

[11] Attin T, Muller T, Patyk A, Lennon AM. Influence of different bleaching systems on fracture toughness and hardness of enamel. Oper Dent 2004; 29: 188-95.

[12] Cantoro A, Goracci C, Vichi A, Mazzoni A, Fadda GM, Ferrari M. Retentive strength and sealing ability of new self-adhesive resin cements in fiber post luting. Dent Mater 2011; 27: 197-204.

[13] Soares CJ, Pereira JC, Valdivia ADCM, Novais VR, Meneses MS. Influence of resin cement and post configuration on bond strength to root dentine. Int Endod J 2012; 45: 136-45.

[14] Dimitrouli M, Geurtsen W, Löhrs A-K. Comparison of the pushout strength of two fiber post systems dependent on different types of resin cements. Clin Oral Invest 2012; 16: 899-908.

[15] Kahnamouei M-A, Mohammad N, Navimipour E-J, Shakerifar M. Push-out bond strength of quartz fiber posts to root canal detin using total-etch and self-adhesive resin cements. Med Oral Patol Oral Cir Bucal 2012; 17: 337-44.

[16] Gomes GM, Gomes OMM, Reis A, Gomes JC, Loguercio AD, Calixto AL. Effect of operator experience on the outcome of fiber post cementation with different resin cements. Oper Dent 2012; 38: 555-64.

[17] Özcan E, Çetin AR, Çapar ID, Tunçdemir AL, Aydinbelge HA. Influence of eugenol on the push-out bond strengths of fiber posts cemented with different types of resin luting agents. Odontology 2013; 101: 204-49.

[18] Özcan E, Çetin AR, Tunçdemir AR, Ülker M. The effect of luting cement thicknesses on the push-out bond strength of fiber post. Acta Odontol Scand 2013; 71: 703-9.

[19] Lee B-S, Lin Y-C, Chen S-F, Chen S-Y, Cahng C-C. Influence of calcium hydroxide dressing and acid etching on the push-out bond strengths of three luting resins to root canal dentin. Clin Oral Invest 2013 [Epub ahead of print].

[20] Martins JD, Bastos LC, Gaglianone LA, Azevedo JFGD, Bezerra RB, Morais PMR. Different alternatives to teeth whitening darkened treated endodontically. J Med Biol Sci 2009; 8: 213-8.

[21] Oliveira DP, Gomes BP, Zaia AA, Souza-filhoFJ, Ferraz CC. In vitro assessment of a gel base containing $2 \%$ chlorhexidine as a sodium perborate's vehicle for intracoronal bleaching of discolored teeth. J Endod 2006; 32: 672-4.

[22] Borges MG, Faria-e-Silva AL, Santos-Filho PCF, Silva FP, Martins LRM, Menezes MS. Does the moment of fiber post cutting influence on the retention to root dentin? Braz Dent J 2015; 26: 141-5.

[23] Costa CL, Xavier OS, Filho SHR, Bond strenght on root dentin in fiber post cementation. Rev Braz Odontol 2009; 66: 117-21.

[24] Uysal T, Er O, Sagsen B, Ustdal A, Akdogan G. Can intracoronally bleached teeth be bonded safely? Am J Orthod Dent Orthop 2009; 136: 689-94.

[25] Ubaldini ALM, Baesso ML, Neto MA, Sato F, Bento AC, Pascotto RC. Hydrogen peroxide diffusion dynamics in dental tissues. J Dent Res 2013; 92: 661-5.

[26] Zhao H, Li X, Wang J, Qu S, Weng J, Zhang X. Characterization of peroxide ions in hydroxyapatite lattice. J Biomed Mater Res 2000; 52: 157-63.

[27] Attin T, Schmidlin PR, Wegehaupt F, Wiegand A. Influence of study design on the impact of bleaching agents on dental enamel microhardness: A review. Dent Mater 2009; 25: 143-57.

[28] Goldberg M, Grootvelt M, Lynch E. Undesirable and adverse effects of tooth-whitening products: A review. Clin Oral Invest 2010; 14: 1-10.

[29] Lehmann N, Debret R, Romeas A, et al. Self-etching increases matrix metalloproteinase expression in the dentin-pulp complex. J Dent Res 2009; 88: 77-82.

[30] Faria-e-Silva AL, Menezes MS, Silva FP, Reis GR, Moraes RR. Intra-radicular dentin treatments and retention of fiber posts with self-adhesive resin cements. Braz Oral Res 2013; 27: 14-9.

[31] Stape THS, Menezes MS, Barreto BCF, Aguiar FHB, Martins LR, Quagliatto PS. Influence of matrix metalloproteinase synthetic inhibitors on dentin microtensile strength of resin cement. Oper Dent 2012; 37: 386-96. 
[32] Marghalani YH. Sorption and solubility characteristics of selfadhesive resin cements. Dent Mater 2012; 28: 187-8.

[33] Lührs A-K, De Munck J, Geurtsen W, Van Meerbeek B. Does inhibition of proteolytic activity improve adhesive luting? Eur J Oral Sci 2013; 121: 121-31.

[34] Toledano M, Yamauti M, Osorio E, Osorio R. Bleaching agents increase metalloproteinases-mediate collagen degradation in dentin. J Endod 2011; 37: 1668-72.

[35] Sung EC, Chan M, Mito R, Caputo AA. Effect of carbamide peroxide bleaching on the shear bond strength of composite to dental bonding agent enhanced enamel. J Prost Dent 1999; 82: 595-8.
[36] Shinohara MS, Peris AR, Pimenta LA, Ambrosano GM. Shear bond strength evaluation of composite resin on enamel and dentin after nonvital bleaching. J Est Rest Dent 2005; 17: 22-9.

[37] Borges AB, Rodrigues JR, Borges ALS, Marsilio AL. The influence of bleaching agents on enamel bond strength of a composite resin according to the storage time. Rev Odontol UNESP 2007; 36: 77-83.

[38] AlEisa K, Al-Dwairi ZN, Lynch E, Lynch CD. In vitro evaluation of the effect of different endodontic sealers on retentive strength of fiber posts. Oper Dent 2013; 38: 539-44.

[39] Macedo VC, Souza NAY, Faria e Silva AL, et al. Pullout Bond Strength of fiber posts luted to different depths and submitted to artificial aging. Oper Dent 2012; 38: E1-6.

Received: August 25, 2015

Revised: September 11,2015

Accepted: September 29, 2015

(C) de Oliveira Moreira et al.; Licensee Bentham Open.

This is an open access article licensed under the terms of the (https://creativecommons.org/licenses/by/4.0/legalcode), which permits unrestricted, noncommercial use, distribution and reproduction in any medium, provided the work is properly cited. 